\title{
Transformaciones urbanas y reivindicaciones ambientales. En torno a la productividad social del conflicto por la construcción de edificios en la Ciudad de Buenos Aires
}

Antonio Azuela. Universidad Nacional Autónoma de México, Ciudad de México, México.

Natalia Cosacov. Universidad de Buenos Aires, Buenos Aires, Argentina.

RESUMEN | En diversas ciudades latinoamericanas la expansión metropolitana es paralela a la densificación de la ciudad central, expresada en la proliferación de desarrollos inmobiliarios que modifican la ciudad construida. Los residentes de esas zonas despliegan acciones de protesta al percibir un deterioro en su entorno. Surgen entonces "conflictos de proximidad" que es relevante analizar, recuperando una de las orientaciones centrales de la sociología del conflicto, que es la de indagar acerca de su productividad social en tres dimensiones: la territorialización, la irrupción del conflicto en el espacio público y la actualización local del derecho. Se pretende contribuir a la comprensión de los recientes conflictos urbanos desde esta perspectiva, mediante el análisis del conflicto que surgió por la construcción de nuevos edificios en la Ciudad de Buenos Aires, poniéndolo en diálogo con un caso de la Ciudad de México, donde han surgido conflictos similares.

Palabras Clave | conflicto social, calidad de vida, participación ciudadana.

ABSTRACT | In several Latin American cities, metropolitan expansions are parallel to the densification of the central city expressed in the proliferation of real estate developments that impact the built city. Residents of those areas display protest actions because they perceive deterioration in their environment. Therefore it is important to analyze some "proximity conflicts" that arise, recovering one of the main orientations of the sociology of conflict, which is to inquire about their social productivity in three dimensions: the territorialization, the eruption of conflict in public space and local updating of the law. This article is an attempt to approach recent urban conflicts from this perspective through the analysis of the conflict that arose from the construction of new buildings in the central zone of the metropolitan area of Buenos Aires, dialoguing with a case from Mexico City, where similar conflicts have emerged.

KEY WORDS | social conflict, quality of life, citizen participation.

Recibido el 16 de junio de 2011, aprobado el 29 de agosto 2012

E-mail: Antonio Azuela, azueladelacueva@gmail.com | Natalia Cosacov, nataliacosacov@gmail.coms 


\section{Introducción}

Entre las transformaciones actuales de las ciudades latinoamericanas destaca la proliferación de proyectos de diversas dimensiones que, al afectar la estructura de los barrios tradicionales de las zonas centrales de las metrópolis latinoamericanas, dan lugar a movilizaciones y conflictos sociales que llegan a convertirse en referentes importantes de la vida política en esas aglomeraciones. Estas movilizaciones se caracterizan por la reivindicación del derecho a la "calidad de vida" y a la participación en las decisiones de política urbana. Quienes se movilizan no pertenecen a los sectores populares, sino a sectores medios, en general propietarios de una vivienda, residentes de barrios abiertos y consolidados de la ciudad central.

En este artículo presentamos un análisis del conflicto que surgió a partir de la construcción de nuevos edificios en el barrio de Caballito, en una zona central del Área Metropolitana de Buenos Aires. Como veremos, el conflicto no solo produjo un cuestionamiento de este tipo de proyectos en la esfera pública, sino que incluso llegó a modificar la normativa urbanística, mediante una intervención del Poder Judicial.

Nos proponemos mostrar que para comprender este tipo de conflictos y sus consecuencias, hay que ir más allá de la agenda de investigación de los movimientos sociales y recurrir a las contribuciones de otras vertientes del pensamiento sociológico. Existen conflictos cuya relevancia sociológica está dada por su productividad social, más que por la indagación de las formas que asume la movilización o el modo en que se constituyen actores colectivos, que es el foco de indagación de las teorías de los movimientos sociales y la acción colectiva.

En particular, tratamos de recuperar una de las orientaciones centrales de la sociología del conflicto, que es indagar acerca de su productividad social. Si desde Simmel (1918) y Coser (1961) está en el horizonte de la sociología la idea de que el conflicto produce orden, en años recientes han aparecido propuestas que ayudan a construir una agenda cada vez más completa para abordar esa cuestión. Particularmente, aquellos aportes que -como señala Naishtat (2005) - están imbuidos del pragmatismo estadounidense y que desde allí establecen un diálogo con la literatura sociológica sobre movimientos sociales (Cefaï, 2001; Melé, 2003a y 2003b; Chateauraynaud, 2008).

Apoyados también en investigaciones latinoamericanas sobre conflictos urbanos y ambientales que son antecedentes valiosos (Sabatini, 1997; Nardacchione, 2005; Merlinsky, 2009; Azuela, 2006; Azuela \& Mussetta, 2009), exploraremos tres aspectos de la productividad del conflicto que nos ocupa: la irrupción del conflicto en el espacio público, la territorialización y la actualización local del derecho. Esto último amerita un comentario especial: no solamente aparece, en las prácticas discursivas de los actores movilizados, una expectativa ampliamente compartida en el sentido de que el derecho regule los procesos de urbanización; además, se observa que, en casos como el nuestro, el conflicto produjo transformaciones nada triviales en el terreno estrictamente jurídico. Esto merecería un acercamiento entre el 
estudio de este tipo de conflictos y la sociología jurídica, aunque en este trabajo no podemos avanzar en esa dirección, por razones de espacio. ${ }^{1}$ Sin embargo, y con el fin de ilustrar la diversidad de los regímenes jurídicos de las ciudades latinoamericanas en este aspecto, y de las consecuencias sociales de esa diversidad, haremos en las conclusiones una serie de referencias al caso de la Ciudad de México, donde han surgido conflictos similares al de Caballito en Buenos Aires, y que han tenido un destino diferente en cuanto a su productividad en el terreno jurídico.

\section{Juego de actores y juego de argumentos}

Colocar en el centro del análisis el conflicto implica asumir una postura analítica que se haga cargo de las limitaciones, así como de las contribuciones, de las miradas consensualistas de lo social. Como señalan Cefaï (2001), Melé (2003a; 2003b) y Chateauraynaud (2008), se trata de pensar el antagonismo, pero no desde una "sociología cínica" que reduce todo a las relaciones de fuerza, sino también considerando los recursos cognitivos, los repertorios de argumentos y las normas morales que utilizan los actores para hacer valer una contestación y así ganar una contienda. El análisis que proponemos sobre el conflicto se enmarca en una sociología de las controversias colectivas, una capaz de pensar, dentro del mismo marco, tanto las relaciones de fuerza como los repertorios argumentativos utilizados por los actores. Esto supone partir del hecho de que "lo público" se instituye mediante de un trabajo colectivo de actores que, partiendo de una situación que definen como problemática, despliegan repertorios de argumentos acordes a ciertas gramáticas públicas, en un intento de interpelar a otros y colocar como común y general aquello que se está afectando. Es con ese tipo de mirada que queremos observar la irrupción del conflicto urbano en la esfera pública de la Ciudad de Buenos Aires. Anticipando el análisis, se destaca en este conflicto cómo el "argumento ambiental" funcionó como repertorio eficaz, logrando inscribir la controversia sobre la densificación y verticalización del barrio como referida a un potencial daño ambiental, lo que amplió los públicos, le otorgó legitimidad a la demanda y la transformó en un derecho exigible.

\section{Los conflictos territoriales}

Hay muchos motivos que pueden dar lugar a desacuerdos. Aquí nos interesan aquellos que se transforman en "conflictos territoriales", los cuales, siguiendo a Sabatini (1997), pueden ser definidos antes que nada como conflictos sociales por el control del territorio, que tienen un carácter multidimensional y distributivo. Como señala el autor, suelen surgir en torno a grandes proyectos productivos, de infraestructura e inmobiliarios originados por cambios en los usos del suelo y por la distribución de esas externalidades. Mientras en algunas situaciones los actores públicos son

1 Nos referimos al hecho de que las corrientes más innovadoras en el campo de la sociología jurídica ponen en duda que el papel regulatorio del derecho sea lo más importante en el estudio de las relaciones entre derecho y sociedad. Véase, por ejemplo, la polémica entre Teubner (1991) y Rottlethuner (1989). 
cuestionados por haber permitido cierto tipo de utilización o por no haber impedido un proyecto privado, en otras son los actores públicos los promotores de la construcción de una infraestructura en una localización determinada que es resistida (Melé, 2003a). En cualquier caso, estos conflictos irrumpen cuando se hacen públicos y comienza una contienda sobre cómo representar, significar y estructurar el espacio urbano.

En ese trabajo colectivo de tornar público un desacuerdo sobre las representaciones de un espacio y de sus usos adecuados, se fue produciendo en Caballito una definición territorial que delimitó el espacio que era preciso proteger y preservar de ciertas dinámicas y, en ese proceso, se incrementaron también las interacciones sociales entre los residentes. Lo que está en juego en este aspecto es cómo un espacio geográfico y administrativo se convierte en un territorio que pasa a orientar las acciones y visiones de los diferentes actores anudados en una contienda pública. En el análisis, entonces, se incorpora el proceso de territorialización que el conflicto detona. Esta noción se orienta a hacer visible cómo conflictos de este tipo producen y redefinen el territorio, así como las relaciones que se entablan con él (Cfr. Melé, 2003a, 2003b; Azuela \& Mussetta, 2009; Merlinsky, 2009).

Finalmente, parte de la productividad social del conflicto que abordamos está dada por el modo en que produce una actualización local del derecho. Esto implica, por un lado, analizar su juridificación, es decir, el proceso social mediante el cual el conflicto es re-significado al ingresar a la esfera del derecho (Azuela, 2006). Por otro lado, dar cuenta de cómo la normativa urbana resultó modificada por el conflicto.

Este artículo explora la productividad social del conflicto que emergió en el barrio porteño de Caballito en los tres aspectos mencionados, pero se inscribe en un objetivo mayor: afirmar la importancia sociológica de analizar el papel de los conflictos en la producción del orden urbano, y la necesidad de examinar los usos sociales y políticos del derecho -en particular, el derecho ambiental y urbano-, porque siguen vigentes las expectativas sobre su poder de regulación. Para ello se nutre de un extenso trabajo de campo realizado entre 2006 y 2008, compuesto por observaciones etnográficas en las protestas públicas y en diversas reuniones que los vecinos movilizados mantuvieron con funcionarios municipales y legisladores, así como entrevistas a diferentes informantes clave (legisladores y periodistas) y a referentes de organizaciones barriales vinculadas a esta protesta. También se apoya en datos estadísticos que permiten contextualizar el conflicto en la dinámica inmobiliaria y demográfica de la Ciudad de Buenos Aires.

\section{El "boom inmobiliario" y su impacto en Caballito}

Luego de la crisis de 2001 y la posterior devaluación del peso en 2002, la economía argentina comenzó un proceso de recuperación y crecimiento sostenido. Una de las actividades donde fue notable es en el sector de la construcción. Como indicador, se muestra en el Cuadro 1 la dinámica de los permisos de obra en la Ciudad 
de Buenos Aires. Mientras que en 2002 cayeron a 690, al año siguiente fueron un poco más del doble, mostrando un crecimiento continuo en los años posteriores hasta 2008, momento de la crisis financiera mundial. Este dinamismo se expresó en la proliferación de obras en construcción, en su mayoría destinadas a nuevas viviendas. A los fines de avanzar en la comprensión del conflicto que abordaremos, es importante señalar que más del 50\% de esas viviendas nuevas se distribuyó entre seis de los cuarenta y ocho barrios de la ciudad, dato que expresa un alto grado de concentración del "boom inmobiliario".

CUADro 1 | Permisos otorgados y superficie cubierta. Ciudad de Buenos Aires, años 2001-2008

\begin{tabular}{|c|c|c|}
\hline Año & PERMISOS & $\begin{array}{c}\text { SUPERFICIE } \\
\text { CUBIERTA }\left(\mathbf{M}^{2}\right)\end{array}$ \\
\hline 2001 & 1.307 & 1.027 .069 \\
\hline 2002 & 690 & 297.867 \\
\hline 2003 & 1.509 & 1.284 .977 \\
\hline 2004 & 1.822 & 1.382 .557 \\
\hline 2005 & 2.142 & 2.160 .872 \\
\hline 2006 & 2.779 & 3.103 .450 \\
\hline 2007 & 2.589 & 3.088 .901 \\
\hline 2008 & 2.172 & 2.713 .597 \\
\hline
\end{tabular}

Fuente Anuario Estadístico 2008. Dirección General de Estadística y Censos del Gobierno de la CiuDAD De Buenos Aires (DGEyC / GCBA).

Como señala Baer (2006), las zonas más demandadas para la construcción de nuevas viviendas fueron aquellas que presentan altas densidades, poseen buena accesibilidad al centro, alta calidad urbana, cercanía a centros comerciales y de servicios y un nivel socioeconómico homogéneo de sus habitantes. La selectividad de la zona también fue acorde al tipo de vivienda que se construyó de manera predominante: multiviviendas destinadas a sectores medios altos y altos (Welch Guerra \& Valentini, 2005; Duarte, 2006; Szajnberg \& Cordara, 2007; Baer, 2008).

Caballito, barrio donde se desató el conflicto que analizaremos, es uno de los seis barrios donde se localizó una gran proporción de emprendimientos residenciales. Del total de viviendas construidas en la ciudad en el periodo 2000-2009, el $10,4 \%$ se concentró en esta zona. En algunas partes del barrio esto implicó que de manera simultánea se registrara un edificio en construcción por manzana (Informe Reporte Inmobiliario, 2008). Los datos del Censo 2010 muestran que entre 2001 y 2010 se incorporaron al barrio 6.000 nuevos residentes, lo que significó un crecimiento del $3,4 \%$ de su población, revirtiendo el sentido decreciente que se registró en el período intercensal anterior (1991-2001). 
Caballito está ubicado en el centro geográfico de la Ciudad de Buenos Aires. Allí convergen una línea ferroviaria, dos líneas de trenes subterráneos y una gran cantidad de líneas de colectivos que lo comunican con diversos puntos de la ciudad. El barrio tiene un tejido urbano continuo, dotado con la infraestructura y el equipamiento propios de un espacio urbano consolidado. Tiene zonas donde predominan edificios y otras que presentan un marcado carácter residencial de baja densidad; es una de las zonas más densas de la ciudad (27.000 habitantes por $\mathrm{km}^{2}$ ) y con menor extensión de espacios verdes (menos de 27 ha).

Podemos resumir en tres los procesos de transformación del barrio en los últimos años: un creciente "proceso de verticalización", que ha implicado la demolición del tejido existente y su sustitución por usos más intensivos del suelo, reemplazando casas por edificios o torres; cambios en los usos del suelo, sobre todo en predios que antes alojaban actividades productivas -lo que expresa el "proceso de repliegue de la industria" y la tendencia creciente a la "tercerización de la ciudad" (Tella, 2005:35)-; y finalmente, la aparición de tipologías residenciales antes inexistentes en el barrio que dan cuenta de nuevas formas de habitar de los sectores medios urbanos, como las llamadas "torres-country" o "torres amuralladas" (Szanjberg, 2010).

Las condiciones para estas transformaciones se explican en gran medida por una serie de reformas al Código de Planeamiento Urbano (CPU), realizadas en épocas de recesión, que pretendieron justamente estimular la actividad inmobiliaria y de la construcción aumentando las capacidades constructivas y ampliando las alturas permitidas (Ciccolella \& Mignaqui, 2008). Como señalan estos autores, las reformas al Código de Planeamiento Urbano, la de 1989 primero y la del año 2000 después, obraron como disparador de una segunda y tercera etapa de densificación vertical del tejido residencial. Mientras el primer proceso de densificación está vinculado a la aprobación del Código de Planeamiento de 1977, 2 el conflicto que abordamos se enmarca en la tercera etapa de densificación vertical de la ciudad. Puntualmente, la reforma al CPU del año 2000 se centró "en el aumento de edificabilidad de distritos centrales barriales, profundizando el proceso de sustitución del tejido edilicio residencial tradicional y aumentando la presión inmobiliaria sobre los pocos lotes vacantes" (ídem, p. 56).

Con la salida de la crisis y el auge de la construcción, se pusieron en evidencia las posibilidades constructivas que las reformas del año 2000 al CPU permitían, y se concretaron en forma casi excluyente en solo algunos barrios.

\section{La activación del conflicto "contra las torres y edificios"}

Este conflicto tiene una particularidad en relación con quienes se movilizan: se trata de personas que tienen un anclaje espacial compartido, lo cual no necesariamente significa que todos tengan, desde el inicio, una visión compartida sobre ese espacio ni una intensa sociabilidad. Precisamente interesa poner de relieve cómo, a partir

Ordenanza MCBA 333867/77.

3 En este apartado lo que se coloca entre comillas es el discurso de los entrevistados; los nombres han sido modificados. 
de un conflicto, comienza un proceso de territorialización que supone delimitar un territorio, producir identificaciones e incrementar las interacciones. El proceso de territorialización es una de las dimensiones productivas del conflicto. Es a partir de este que se produce "una visión territorial del anclaje espacial" (Melé, 2003, p. 13). Precisamente, fue a partir del conflicto que residentes próximos comenzaron a vincularse y, en un trabajo colectivo, fueron definiendo una visión compartida de ese espacio que querían defender, de los valores ligados al mismo y de los que residían allí.

José es el referente de una de las organizaciones que surgieron para oponerse a la construcción de edificios en el barrio y fue quien organizó la primera protesta pública. Es vendedor de productos químicos en relación de dependencia, vive en Caballito desde hace treinta y tres años y es propietario de la vivienda en que habita. Su casa, de dos plantas y jardín, está ubicada en la zona norte, donde predominan edificaciones de escasa altura. En el período posdevaluación, esta zona comenzó a transformarse, y hoy es visible el incremento de nuevos emprendimientos inmobiliarios residenciales.

Corría mayo de 2006 cuando comenzó la construcción de un edificio de diez pisos al lado de la casa de José. Como nos contaba en la entrevista, se dirigió a la "municipalidad" para averiguar si esa nueva construcción era legal. Como le comunicaron que se ajustaba al Código de Planeamiento Urbano, decidió, junto con un vecino, "salir a juntar firmas" porque "era necesario cambiar el FOT, que es el Factor de Ocupación del Terreno, es decir, ese porcentaje o esa relación que le permite construir en altura". ${ }^{4}$ Sin embargo, a los pocos días se dio cuenta de que las firmas que iba recabando "bastante fluidamente" terminarían como "papel higiénico de alguna entidad oficial". Decidieron entonces poner un pasacalle que decía: "Vecinos: acá se intenta construir un edificio de diez pisos y alterar las características de nuestro barrio. Unámonos para resistir". Con el tiempo se fueron acercando cada vez más vecinos, algunos porque tenían construcciones al lado de sus casas, y otros porque no querían que se construyeran edificios y torres en el barrio. Hicieron un par de reuniones y decidieron realizar la primera protesta: "Lo que teníamos en claro era que para intentar resolver esto, había que ser muy visibles, no eran las firmas las que iban a cambiar esto. Era un cóctel de los vecinos en la calle y los medios tomando eso" (José, SOS Caballito).

El 2 de junio realizaron la primera protesta, a la que llamaron "La caminata del sol", para resaltar que los nuevos edificios y torres comenzarían a quitarles la luz. Desde aquel día se sucedieron diversas protestas, por momentos casi semanales. En una oportunidad, la consigna con la que convocaron al "banderazo porteño" fue "sí a los barrios, no a las torres". En Acoyte y Rivadavia -la esquina emblemática del barrio- durante una hora cortaron parte de la calzada mientras hacían ruido con

4 El Factor de Ocupación Total es el coeficiente que, multiplicado por la superficie total de la parcela, da como resultado la superficie total máxima edificable. Ese coeficiente depende de la zonificación asignada por el CPU para la zona donde se localiza el terreno. 
cacerolas. ${ }^{5}$ Como parte de la protesta habían construido un edificio de cartón con un techo que se abría como una boca tragándose el sol. Acompañaba la protesta una grabación que aludía a la alta densidad de Caballito, "el barrio con más habitantes por metro cuadrado del país", y se mencionaban como lo que "no queremos ser", las ciudades de São Paulo y Río de Janeiro. La planificación por parte del Estado y la participación de la ciudadanía eran dos demandas centrales. Esas ciudades a las que se aludía condensaban el "caos", el "desborde". Eran lo opuesto a una ciudad "tranquila" y "planificada”. En el Estado se colocaba la capacidad de definir uno u otro rumbo.

A lo largo de manifestaciones y reuniones se fue consolidando el barrio como definición territorial del espacio que era preciso proteger. El barrio de Caballito - recorte administrativo establecido por una ordenanza - logró definir y delimitar un espacio exhaustivo y contiguo sobre el cual los residentes orientaron sus acciones, transformándose de este modo en un territorio. Los conflictos territoriales implican "un trabajo colectivo en torno a las representaciones de los usos legítimos del espacio y una definición territorial que delimite el espacio que es preciso proteger y preservar de ciertas dinámicas" (Melé, 2003, p. 13, traducción nuestra).

La idea del barrio tuvo una particular eficacia simbólica para producir pertenencias e identificaciones. No solo alude a límites administrativos, sino que también es la figura urbana que condensa -en la historia y en el imaginario de Buenos Aires- el reducto de vecindad frente a la urbanidad que presenta el centro (Gorelik, 1998). En un contexto de conflicto o amenaza, es fácilmente invocada para aludir a la comunidad. Y ello más aún frente a la dinámica inmobiliaria que en la percepción de estos vecinos representa el "caos" y el "desborde". La revitalización de la identidad vecinal y del barrio fue el recurso usado para legitimar y conseguir apoyos en una lucha por controlar los usos del suelo y el espacio urbano construido.

[La] articulación con los vecinos nos alegra la vida a todos, porque la verdad que sentimos al lado el tipo que es prójimo nuestro, en la doble acepción, por cercano y porque tiene que ver con nosotros (...). En ese marco la verdad que estamos felices; hemos hecho fiestas con los vecinos; rearmamos, creo, no sé si puedo decirte el viejo barrio que yo pude ver hace cuarenta años, pero sí una cosa desconocida en la Ciudad de Buenos Aires, donde cada uno está ensimismado en sus preocupaciones, en sus problemas... (José, S.O.S. Caballito).

\section{El papel de los medios de comunicación}

Los referentes de las organizaciones coinciden en afirmar que fue muy importante lograr que los medios de comunicación difundieran la situación. De hecho, tenían la expectativa de una respuesta positiva porque, como nos decía José, "no éramos,

5 Desde 2001, como señalan Svampa (2002) y Visacovsky (2009), los "cacerolazos" se vincularon a repertorios de protesta de la "clase media”, que se distinguían de los repertorios de sectores sindicalizados de la clase obrera o de los movimientos de trabajadores desocupados, como las huelgas, cortes de ruta, etcétera. 
con todo el respeto que me merecen los morochos piqueteros ${ }^{6}$ de La Matanza, ${ }^{7}$ no éramos piqueteros de La Matanza. Éramos blanquitos y entonces los canales, todos, daban otra salida”.

Della Porta y Diani (1999) señalan que el éxito de una protesta está relacionado con el grado de atención de los medios que ella recibe. En general se dice que es preciso involucrar a mucha gente, utilizar tácticas radicalizadas o ser particularmente innovador para obtener esa cobertura mediática. Sin embargo, en el caso de esta movilización, esos elementos no estuvieron presentes. Más bien, como señalaba un periodista de Clarín, uno de los tres periódicos más leídos de la República Argentina:

... es más importante un tema menor en Caballito que un tema más grande en otro lugar. (...) la repercusión que puede tener para Clarín es mayor. Sé que de cada diez lectores de Clarín, ocho son de capital. Y dentro de la capital, todo lo que es clase media, media alta. (...) Además, en Caballito vive mucha gente que trabaja en Clarin; entonces, cualquier cosa que pasa en su barrio les molesta o les importa como a cualquiera... más que era la primera vez que había manifestaciones concretas contra el "boom de la construcción". Más los fallos judiciales, que fue uno atrás del otro, se convirtió en un tema muy de la ciudad (Pablo Novillo, periodista de la sección Ciudad, diario Clarín).

La coincidencia entre las expectativas de los vecinos respecto de que los medios les prestarían atención porque no eran "los morochos de La Matanza", y las afirmaciones del periodista de Clarín acerca de los motivos por los cuales la protesta tuvo lugar en la prensa, da cuenta de la existencia de evaluaciones compartidas, producidas socialmente, acerca del carácter selectivo de los medios según sean las identidades sociales de quienes se movilizan. Además de quiénes eran los que se movilizaban, el periodista de Clarín señalaba que la movilización era novedosa porque modificaba la percepción dominante sobre el "boom constructivo", que había sido visto como uno de los ejes de la reactivación económica y de la creación de empleo. Así, se creó una nueva controversia, lo que sin duda aumentó la atención de los medios de comunicación.

\section{La juridificación del conflicto: haciendo cosas con palabras}

Nuestro punto de partida es que las normas jurídicas no deben ser vistas como una especie de "causa eficiente" de los comportamientos deseados por quienes las redactaron, sino como un repertorio al alcance de los actores para actuar frente a determinados eventos cuando ellos se presentan. En el conflicto que nos ocupa, los enunciados de la legislación permitieron a los vecinos presentar sus demandas no solo como aspiraciones legítimas, sino como derechos exigibles. Como ya señalaba

6 Piqueteros" es el modo en que se autodefinieron quienes comenzaron a cortar la ruta a mediados de los años noventa, para reclamar por puestos de trabajo en un contexto de aguda crisis social. Actualmente es usada también por el común de la gente para referirse a ellos.

7 La Matanza es uno de los partidos más pobres del conurbano bonaerense y también uno de los que presenta mayor grado de organización y movilización política. 
Sabatini (1997) en un trabajo pionero, en un conflicto territorial la existencia de "un fallo judicial a favor de una comunidad o grupos de ella (...) eleva considerablemente la fuerza de la parte débil" (p. 85) dentro de la contienda. Es que, además de la fuerza estrictamente normativa del derecho, hay que destacar que el mismo tiene también una enorme fuerza comunicativa. Al invocar enunciados jurídicos ambientales, los vecinos no solo pudieron articular sus demandas como derechos, sino que también difundieron la idea de que lo que estaba en juego era un "daño ambiental"; el discurso jurídico sirvió para transmitir una nueva manera de representar la experiencia social. Con ello el conflicto no solo se llevó al campo jurídico, con las consecuencias que a continuación se describen, sino que además modificó la definición pública del problema. Como señala Steimberg (1999) -recuperando a Austin (1962)-, "la gente hace cosas con palabras y esto tiene consecuencias tan palpables como otras formas de acción, como son las manifestaciones, huelgas y saqueos" (p. 201).

\section{Los recursos de amparo}

Interesa la manera en que los vecinos utilizaron el repertorio jurídico para fundamentar sus demandas -qué figuras jurídicas movilizaron-y el modo en que ello produjo una redefinición del problema en el espacio público. Vale la pena detenernos sobre dos amparos promovidos por miembros de dos organizaciones del barrio. Uno de ellos fue central, porque desembocó en una resolución judicial que ordenó al Gobierno de la Ciudad la suspensión de nuevos permisos en una zona del barrio. Como consecuencia, el Gobierno tuvo que dictar un decreto suspendiendo el otorgamiento de permisos de obra por noventa días para seis barrios de la ciudad, entre ellos, el de Caballito. Como veremos, esto provocó una enérgica reacción por parte de organizaciones empresariales, obreras y profesionales vinculadas a la construcción.

La presentación de los amparos trajo consigo una redefinición del conflicto en tres aspectos. Primero, la cuestión de la regulación de los usos del suelo aparecía ya no como un tema urbano, sino también como un problema ambiental; segundo, el carácter colectivo de la movilización dio paso a la individualización impuesta por el derecho (el "nosotros" fue sustituido en los recursos de amparo por presentaciones individuales). Finalmente, el barrio de Caballito -como definición territorial del espacio que se quería proteger- fue sustituido en las presentaciones judiciales por solo algunas manzanas del barrio.

Los recursos fueron presentados por dos personas que residen en el barrio y que forman parte de dos organizaciones diferentes que surgieron a raíz de este conflicto. Una de ellas vive en la zona sur, la otra en la zona norte del barrio. El recurso de amparo ambiental presentado por Carolina López, de la organización "Vecinos Agrupados de Caballito" de la zona sur, en primer lugar, fundamenta su legitimación para dicha presentación en la Ley General del Ambiente (Ley $\mathrm{N}^{\circ}$ 25675), que en su art. 30 afirma que "producido el daño ambiental colectivo, 
tendrá legitimación para obtener la recomposición del ambiente dañado (...) el afectado...."

En el relato de los hechos, la demanda recurre a estadísticas sobre la dinámica constructiva del barrio y menciona que muchas obras recientes son ilegales, de acuerdo con el Código de Planeamiento Urbano. Se argumenta, por ejemplo, que en zonas declaradas Áreas de Protección Histórica se han autorizado demoliciones y construcciones de multiviviendas. Por otra parte, se sostiene que aunque otras obras presentes en el barrio sí se ajustan al Código, si se las considera en conjunto superan el mínimo exigido por la Ley de Evaluación de Impacto Ambiental (Ley $\mathrm{N}^{\circ} 123$ ), por lo que esta sería exigible. Al no realizarla se violaría también el derecho de los vecinos a participar de una audiencia pública a las que alude la norma mencionada en su art. 9. Se insiste en que más allá de lo dispuesto por el CPU, lo importante es reconocer la afectación al medioambiente, por lo que se produce "una violación al concepto medioambiental del paisaje y entorno urbano tutelado en nuestra normativa", tal como lo establece la Ley General del Ambiente (Ley $\mathrm{N}^{\circ}$ 25675). ${ }^{8}$ Finalmente se afirma que no han sido considerados los principios rectores en materia ambiental, de precaución y prevención (art. $4^{\circ}$ de la Ley $\mathrm{N}^{\circ} 25675$ ), que establecen la obligación de anticiparse a la producción del daño ambiental, más allá de que sus efectos sean inciertos, dudosos o poco probables. El amparo solicita que se revoquen las autorizaciones de obra otorgadas para la construcción de los inmuebles ubicados en una zona de más de 45 manzanas del barrio -mientras que el barrio en su totalidad cuenta con 485 manzanas-, así como una medida cautelar de "no innovar" para que no se otorguen más permisos de obra en esa zona.

En el otro recurso de amparo, presentado por José Fernández, de la organización "S.O.S. Caballito", la argumentación fue similar, en el sentido de que señala que la dinámica inmobiliaria podría generar un "daño ambiental" y que con ello se estaría violando tanto la Constitución Nacional $(\mathrm{CN})^{9}$ como la Constitución de la Ciudad Autónoma de Buenos Aires (CCABA). ${ }^{10} \mathrm{Al}$ mismo tiempo, señala el incumplimiento de la Ley $\mathrm{N}^{\circ} 123$ (Ley de Impacto Ambiental de la Ciudad) por parte de los desarrolladores, con el mismo argumento de los "efectos acumulados", que harían exigible la realización de una Evaluación de Impacto Ambiental (EIA). Por lo tanto, se solicita que se ordene la suspensión de la construcción de todas las obras autorizadas o en trámite que se estén ejecutando en una zona

8 Para una interpretación jurídica del tema, véase Di Paola (2008).

$9 \mathrm{El}$ art. 41 de la CN, expresa que "todos los habitantes gozan del derecho a un ambiente sano, equilibrado, apto para el desarrollo humano y para que las actividades productivas satisfagan las necesidades presentes sin comprometer las de las generaciones futuras; y tienen el deber de preservarlo. El daño ambiental generará prioritariamente la obligación de recomponer, según lo establezca la ley. Las autoridades proveerán a la protección de este derecho, a la utilización racional de los recursos naturales, a la preservación del patrimonio natural y cultural y de la diversidad biológica, y a la información y educación ambientales".

10 El art. 26 de la CCABA dispone: "El ambiente es patrimonio común. Toda persona tiene derecho a gozar de un ambiente sano, así como el deber de preservarlo y defenderlo en provecho de las generaciones presentes y futuras. Toda actividad que suponga en forma actual o inminente un daño al ambiente debe cesar. El daño ambiental conlleva prioritariamente la obligación de recomponer". 
de dieciséis manzanas y la prohibición de emisión de nuevos permisos mientras no se realice un estudio sobre los efectos de las nuevas construcciones. En esta presentación judicial tampoco se tomaba ya al barrio en su conjunto, sino que se acotaba a algunas zonas.

\section{La argumentación judicial}

El fallo que respondió a ese último recurso de amparo y que constituyó un punto de inflexión en el desarrollo del conflicto fue dictado por la jueza Petrella, de Primera Instancia en lo Contencioso Administrativo y Tributario de la Ciudad Autónoma de Buenos Aires. El fallo parte de considerar legítima la presentación del recurso de amparo con fundamento en la CN y en la CCABA. Señala que al demandante no solo le asiste un derecho reconocido por ambas constituciones, sino que a ello "debe sumarse un interés legítimo como vecino de la zona”. La jueza señala que la Constitución proclama el deber de preservar el medioambiente y defenderlo en provecho de las generaciones presentes y futuras y que "dadas las especiales características del daño ambiental, tiene fundamental preeminencia la prevención del daño, y es el Estado el garante del derecho humano a un ambiente sano".

El fallo reconoce que si bien en principio cada una de las obras individualmente no superaría la superficie puesta como parámetro para exigir una Evaluación de Impacto Ambiental, tomadas las obras en conjunto sí lo superarían ampliamente. El argumento es que partiendo de que es el Estado el garante del ambiente, todo emprendimiento que pudiera ser susceptible de generar alteraciones o perjuicios degradantes al entorno debe encontrar límites jurídicos razonables, y que la herramienta predictiva llamada a determinarlos es la EIA. Al no realizarse, la jueza afirma que es "imposible predecir los efectos que la ejecución de los proyectos tendrá sobre los componentes del medio". El fallo se sustenta en que la CCABA refleja la decisión de prevenir prioritariamente deterioros ambientales antes de tener que encarar su reparación y rechaza el concepto del "contaminador pagador", obligando a preservar y defender, antes de recomponer. El fallo concluye dando lugar al recurso de amparo ambiental y dispone que "el GCBA [Gobierno de la Ciudad de Buenos Aires] se abstenga de otorgar nuevos permisos de demolición o de obra” en dieciséis manzanas ${ }^{11}$ hasta tanto se dicte sentencia de fondo.

\section{Los efectos del recurso judicial: la “ambientalización” del conflicto}

Luego del fallo, el conflicto ya no era el mismo. Si originalmente estaba definido como una controversia por los "usos del suelo", se trasladaba ahora a un campo más amplio de problemas, acercando las demandas de estos vecinos a la de otro grupo de actores: los “ambientalistas". A finales de 2007, los vecinos de Caballito participaron de la Marcha Nacional Ambiental que reunió a diversas organizaciones

11 Delimitadas por las calles Paysandú, Arengreen, Martín de Gaínza y Gaona. 
"contra la contaminación ambiental y el saqueo". Confluyendo con movimientos y asociaciones rurales y urbanas que ponían en el centro de las demandas "la protección de los bienes comunes", los vecinos de Caballito pudieron ir desplazando el carácter particularista y "vecinalista" de su protesta (Nardacchione, 2005), para enmarcar la movilización "contra los edificios y torres" en un cuestionamiento al modelo de desarrollo, las corporaciones empresariales y el rol del Estado. Así, el emergente movimiento socioambiental ofreció un marco propicio para la movilización vecinal (Zald, 1999).

Por otra parte, con el conflicto se había evidenciado una tensión entre la ciudad tal como la define el Código de Planeamiento Urbano (1977) ${ }^{12}$ y la ciudad deseada por estos grupos de residentes, cuyos reclamos se dirigían básicamente hacia construcciones que consideraban inadecuadas, aun siendo legales. No había un reclamo, por tratarse de operaciones inmobiliarias posibles por "excepciones" al Código de Planeamiento Urbano. El modo en que estos vecinos pudieron hacer valer esas expectativas como derechos -y desde allí plantear una confrontación con lo postulado por la normativa urbanística vigente (CPU) - fue invocar la normativa ambiental.

La apelación a la normativa ambiental, que al mismo tiempo mostraba los límites de la legislación urbanística, actualizó un debate ya planteado acerca de la necesidad de aprobar el Plan Urbano Ambiental, como lo estipula desde 1996 la Constitución de la Ciudad. El conflicto aquí analizado aceleró los tiempos de la legislatura, y el 23 de noviembre de 2008 se aprobaba el Plan Urbano Ambiental. ${ }^{13}$ En este punto hay que decir que la jueza Petrella, reflexionando sobre el procedimiento, pero fuera de él, expresó que "si el plan [Plan Urbano Ambiental] existiera, los jueces no tendrían por qué interpretar permanentemente los temas urbanísticos como lo vienen haciendo (...). Resulta paradójico: por un lado, se señala a los jueces porque invaden esferas propias de otros poderes, pero estos no ejercen las funciones constitucionales que les fueran asignadas. Por ende, ante la lesión de un derecho constitucional por omisión, no le queda al juez otra alternativa que reestablecer el derecho conculcado". ${ }^{14}$

Finalmente, el paso del conflicto por el recurso judicial tuvo otro efecto, que fue el de sumar más actores a la disputa. Recordemos que el fallo se orientó a exigir la intervención del Poder Ejecutivo. Como veremos, el decreto que suspendió el otorgamiento de permisos de obra generó que una diversidad de actores -que hasta ese momento no habían expresado sus posiciones- se manifestaran públicamente en relación con este tema.

12 La aprobación del Código de Planeamiento Urbano data de 1977, pero sufrió reformas significativas en 1989 primero y en 2000 después. Como señalan Ciccolella y Mignaqui (2008), ambas obraron como disparador de una segunda y tercera etapa de densificación vertical del tejido residencial.

13 Sin embargo, hay que decir que hasta tanto ese plan no se traduzca en una serie de nuevos códigos (urbanístico, morfológico, ambiental, etcétera), será el actual Código de Planeamiento Urbano el que regirá los usos del suelo de la ciudad.

14 Ponencia presentada por la jueza Petrella en el Congreso Internacional de Derecho Ambiental, bajo el título "Conflictos entre desarrollo inmobiliario y protección ambiental". Buenos Aires, 2008. 


\section{La intervención del Poder Ejecutivo}

El fallo judicial sobre Caballito había consolidado la idea acerca de que se estaba frente a un posible "daño ambiental". Con ello, la urgencia y el riesgo se instalaron. A partir de entonces, el jefe de gobierno de la Ciudad -en ese momento, Jorge Telermandictó un decreto de suspensión de los permisos de construcción por noventa días. ${ }^{15}$ El decreto se fundamentaba "en la necesidad de evaluar los efectos que el crecimiento edilicio provocará sobre la infraestructura de servicios disponibles, en atención a la calidad de vida de la población, y en consecuencia determinar el impacto que pudiera suscitar el aumento de construcciones o modificaciones edilicias en ciertas zonas de la ciudad, a fin de estudiar la posibilidad de eventuales daños al medioambiente urbano y a su infraestructura". La suspensión incluía los permisos de obra de viviendas de tipo multifamiliar o colectivas cuando su altura superara la correspondiente a un distrito de baja densidad. El decreto, por cierto, no abarcaba todos los barrios de la ciudad, sino solo seis de ellos: Villa Urquiza, Coghlan, Núñez, Palermo, Villa Pueyrredón y Caballito. A partir de ese decreto, el Ministerio de Planeamiento y Obras Públicas requirió informes a las diversas empresas prestatarias de los servicios públicos para que dieran cuenta de la disponibilidad de infraestructura y del estado del servicio en esos barrios.

La respuesta a ese decreto por parte de los actores interesados en el mercado inmobiliario y de la construcción no se hizo esperar. ${ }^{16}$ Se registró una importante cantidad de consultas de empresarios de la construcción a estudios jurídicos para cuestionar el decreto por vía judicial, ${ }^{17}$ y a la semana se convocó a una protesta pública. El 22 de noviembre, frente a la jefatura de gobierno, unas trescientas personas reclamaban contra la suspensión de los permisos. Además de empresarios de la construcción, estaban los obreros. Portaban unos paraguas donde se leía "Construcción sí, desocupación, no". Otras pancartas decían "Caballito no colapsa, se levanta". Presentaron al Ejecutivo un petitorio donde afirmaban que "en un Estado de derecho, la firma de decretos que atenten contra las leyes provoca un estado de inseguridad jurídica. Hay procedimientos legislativos en el mismo Código para su modificación". Al día siguiente, los vecinos realizaron una protesta a la que llamaron "ruidazo porteño", con el objeto de mostrar que para ellos el decreto del Ejecutivo no era suficiente para resolver el problema, y en este punto coincidían con los actores de la construcción en que era necesaria una ley que reformara el Código de Planeamiento Urbano, que contemplara densidades y fisonomías de los barrios e infraestructura disponible.

Unos meses después, el 4 de enero de 2007, diversas cámaras empresariales y asociaciones obreras vinculadas a la construcción publicaron una solicitada en el diario

15 Decreto $N^{\circ}$ 1929/06 del 13 de noviembre de 2006.

16 “¿Por qué se quiere destruir el mercado inmobiliario?”. Así tituló la Cámara Inmobiliaria Argentina un comunicado de prensa publicado en su página (http://www.cia.org.ar), en La Nación y en Clarín (23 y 26 de diciembre de 2006, respectivamente); “Con el freno todos pierden”, título de la entrevista a F. Prati, presidente del Consejo de Profesionales de Arquitectura y Urbanismo, en Suplemento Arquitectura, Clarín, 2 de enero de 2007.

17 “Tuvimos más de treinta consultas en un solo día”, confirma Daniel E. Butlow, uno de los abogados del estudio Butlow y Nerpiti, especializado en el tema (Diario Judicial, 17 de noviembre de 2006). 
Clarín bajo el título "El corralito de Telerman". Mencionaban que el decreto era una "medida elitista", ya que la "suspensión de obras de viviendas en seiscientas manzanas de barrios de clase media expulsa a los habitantes al conurbano e impide el ingreso de nuevos vecinos". También señalaban que la medida "desalienta la construcción de departamentos pequeños y medianos, haciendo crecer el déficit habitacional de vivienda de los sectores medios y bajos, que verán cada vez más cara e inaccesible la vivienda para ellos y sus hijos". Además de marcar el efecto que tendría el decreto sobre el mercado de viviendas para sectores medios y bajos, se mencionaba que la medida iba a contrapelo de las políticas orientadas a reactivar la economía.

Por su parte, los vecinos orientaron su discurso en torno a la falta de intervención del gobierno en la planificación, definiéndose a sí mismos como los "ciudadanos con derechos" frente al "capital inmobiliario especulativo" que "solo busca de la ciudad hacer negocios a cualquier costo", dejándolos sin agua y con las cloacas "colapsadas" y "arrasando" inmuebles con valor histórico y cultural, así como "explotando" a los trabajadores sin otorgarles un mínimo de seguridad. ${ }^{18}$

Claramente el conflicto se había instalado como un "problema público", creando una escena y una temporalidad donde se intercambiaban argumentos, y se volvían visibles las diferentes formas de justificación, las representaciones del espacio urbano y los distintos registros de legitimidad. Con el paso del tiempo comenzaron a surgir distintas organizaciones en otros barrios que tomaron como referencia la movilización de los vecinos de Caballito.

En febrero de 2007, Telerman levantó el "corralito inmobiliario" mediante otro decreto. ${ }^{19}$ Recordemos que el anterior decreto, además de suspender los permisos de obra por noventa días, había planteado la necesidad de conocer el estado de la infraestructura de servicios públicos (gas, luz y agua). De los diferentes informes que entregaron las empresas prestatarias de servicios, la única que reconoció una situación altamente crítica en el estado de la infraestructura fue Agua y Saneamientos Argentinos S.A (AySA). ${ }^{20} \mathrm{El}$ nuevo decreto, que derogaba el anterior, estableció que en los trámites de permisos de obra con destino a vivienda multifamiliar se exigiría el Certificado de Factibilidad Técnica e Hídrica. ${ }^{21} \mathrm{Al}$ mismo tiempo, estableció que los emprendimientos superiores a 5.000 metros cuadrados debían someterse a la EIA, prevista en la Ley $\mathrm{N}^{\circ} 123$.

A partir de allí, la discusión giró hacia la necesidad de debatir el modelo de ciudad y el papel de la planificación. En los meses siguientes se publicaron diversas notas

18 En un volante que convocaba a la marcha se hablaba de "un modelo de crecimiento especulativo que no tiene reparo por la vida de obreros, vecinos, propiedades o bienes. Solo importa la maximización de la ganancia”.

19 El 15 de febrero de 2007 se dictó el Decreto $N^{\circ} 220 / 07$ en reemplazo del anterior ( $\left.N^{\circ} 1929\right)$, que tenía una vigencia de noventa días.

20 Hay que destacar que, de las tres prestatarias, AySA es la única empresa estatal. Si bien el tema escapa a este trabajo, habría que reflexionar si no fue precisamente el carácter estatal de esta empresa lo que le otorgó mayor independencia que a las otras, ya que un reconocimiento por parte de aquellas sobre un estado crítico de las infraestructuras habría tenido efectos sobre la concesión del servicio.

21 Esto era solo para aquellas obras que superaran los 13,5 metros de altura en los barrios de Caballito, Coghlan, Palermo, Villa Pueyrredón y Villa Urquiza. El barrio de Núñez quedaba excluido de este segundo decreto, debido a que e informe de AySA aseguraba que en ese barrio la infraestructura disponible sí podía soportar nuevas construcciones. 
de opinión de especialistas y se realizaron charlas en torno a este tema. Los vecinos habían logrado construir la "situación problemática" como un "problema público" alrededor del cual se debatían argumentos, se desplegaban saberes técnicos y jurídicos y se movilizaban recursos diversos para orientar las decisiones.

\section{La intervención de la Legislatura}

Hasta aquí hemos dicho que la presentación de los recursos de amparo y el fallo de la jueza constituyeron un "hito" en el desarrollo que asumió el conflicto. Sin embargo, las diferentes medidas que tomó el Ejecutivo estuvieron lejos de cerrar la controversia. Los actores del sector de la construcción vivían como una fuente de incertidumbre e inseguridad jurídica el que se modificaran las "reglas de juego" por medio de decretos. Afirmaban que existía un Código de Planeamiento Urbano que era necesario respetar o, en todo caso, modificar mediante leyes y del procedimiento pautado por el propio Código. Los vecinos movilizados tampoco se conformaban con los decretos emitidos por el Ejecutivo. Exigían una modificación del CPU que cambiara la zonificación del barrio, a una de menor densidad para disminuir las alturas y volúmenes edificables. En otras palabras, las dos partes enfrentadas, tanto vecinos como empresarios, expresaban una adhesión al Código como instancia de regulación de los procesos urbanos.

La primera medida que tomó la Legislatura fue modificar el CPU en relación con los requisitos para autorizar nuevas construcciones. Mediante la Ley $\mathrm{N}^{\circ} 2359,{ }^{22}$ se introducía en el Código algo que hasta ese momento no era contemplado: previa autorización para la construcción de una vivienda multifamiliar, se debía certificar que existía una disponibilidad de los servicios públicos. Las empresas prestatarias debían manifestar que la infraestructura instalada de gas, agua y electricidad sería suficiente para satisfacer la nueva demanda que generaría la obra.

Desde la perspectiva de los vecinos, la reforma al Código no resultaba suficiente. Ellos querían que se modificara la zonificación del barrio a "residencial de baja densidad". Esa postura comenzó a tener eco en algunos legisladores. El 2 de octubre del 2007 se presentaron en la Comisión de Planeamiento Urbano de la legislatura cuatro proyectos de distintos legisladores para rezonificar el barrio. Los vecinos habían logrado colocar el problema de Caballito en la agenda legislativa.

Algunos de los factores que concurrieron para influir en esa agenda eran señalados por una diputada que intervino en la cuestión. Mencionaba que muchos legisladores se fueron haciendo eco de la reivindicación de estos vecinos en torno a la "calidad de vida" y que además no era menor quiénes eran los que se movilizaban:

...los vecinos instalaron en la agenda el problema. Ellos lo que planteaban concretamente era que se les estaba alterando la calidad de vida, como un valor diferente, más allá del negocio inmobiliario (...). Estas personas viven en un lugar

22 Veintiocho de junio de 2007, Boletín Oficial de la Ciudad Autónoma de Buenos Aires (BOCBA), N².736, del 31/07/2007. 
determinado, eligieron vivir en un barrio bajo, ¿por qué se les va a modificar su calidad de vida? Por otra parte, también es cierto que no es lo mismo una protesta en Scalabrini y Santa Fe [Palermo] o Acoyte y Rivadavia [Caballito]; te digo porque los de la zona sur han tocado mil puertas y no han logrado la zonificación (entrevista a diputada Beatriz Baltroc).

Sin duda existe una geografía desigual de los recursos materiales y simbólicos que opera en la capacidad de incidir en el poder público. La selectividad que habían mostrado los medios también está presente en el ámbito del gobierno de la ciudad. Además del capital social de estos vecinos, el capital cultural desempeñó un papel importante en los recursos que desplegaron para hacer cumplir sus demandas. En las reuniones de las comisiones de la legislatura, los vecinos de Caballito fueron capaces de diluir las fronteras entre autoridades y vecinos por la forma de presentarse ante los legisladores, el modo de expresar sus demandas y, sobre todo, por el manejo de la normativa e informes estadísticos de la construcción. Si bien algunos, por sus profesiones, ya conocían la normativa y los procedimientos administrativos, otros fueron aprendiendo en el conflicto y se transformaron en verdaderos conocedores. La legisladora a la que entrevistamos se refería a esto nombrando a los vecinos como "expertos".

En el año 2008 se votaron dos leyes por unanimidad mediante las cuales se rezonificaron $^{23}$ algunas de las áreas del barrio de Caballito. La legislatura no hizo un tratamiento general sobre el problema del crecimiento de la ciudad, de la densificación y verticalización, sino que restringió el tratamiento a ciertas zonas puntuales, concentrándose en las zonas de mayor presión y visibilidad pública.

A modo de síntesis, la Figura 1 muestra cómo cada instancia por la que circuló el conflicto modificó la delimitación del territorio que quedaría bajo protección. En negro y blanco se marcan los límites del fallo dictado por la jueza Petrella, en respuesta favorable al recurso de amparo ambiental presentado por el vecino José Fernández. En negro se delinean los límites del barrio, ámbito afectado en su totalidad por el decreto del Ejecutivo que frenó las autorizaciones de nuevas obras, respondiendo al fallo judicial. En gris se presentan las zonas que resultaron modificadas por los cambios realizados al CPU mediante de las leyes de la legislatura.

La diferencia entre la zona delimitada por el fallo judicial y la delimitada por las leyes se vincula a dos motivos. Conviene recordar que los vecinos siempre reivindicaron el barrio en su totalidad como territorio sujeto a protección. Fue la esfera judicial la que los obligó a restringir la demanda a unas cuantas manzanas. Pero fuera de ese ámbito, continuaron exigiendo una respuesta que abarcase la totalidad de Caballito. Esto se expresó de manera muy clara al momento de discutir con los legisladores. El segundo motivo está vinculado a que existieron dos fallos más, además del mencionado, que dieron lugar a recursos de amparo presentados por los

23 Rezonificar: modificar la zonificación que aparece en el Código de Planeamiento Urbano, donde se establecen usos y densidades. Los usos pueden ser comercial, residencial, industrial, etcétera; y las densidades, baja, mediana y alta. En el caso de Caballito, las leyes 2721/08 y la 2722/08 modificaron la zonificación de algunas áreas del barrio, de zonas de alta densidad a baja. 
vecinos. ${ }^{24}$ Aunque su efecto en el espacio público fue mucho menor, debido a que el camino ya estaba allanado, influyeron al momento de la discusión legislativa ampliando el repertorio de pruebas que los vecinos pudieron mostrar para convencer a los legisladores de que era necesario rezonificar la totalidad de las manzanas del territorio barrial.

FIGURA 1 | La productividad jurídica del conflicto en el territorio barrial

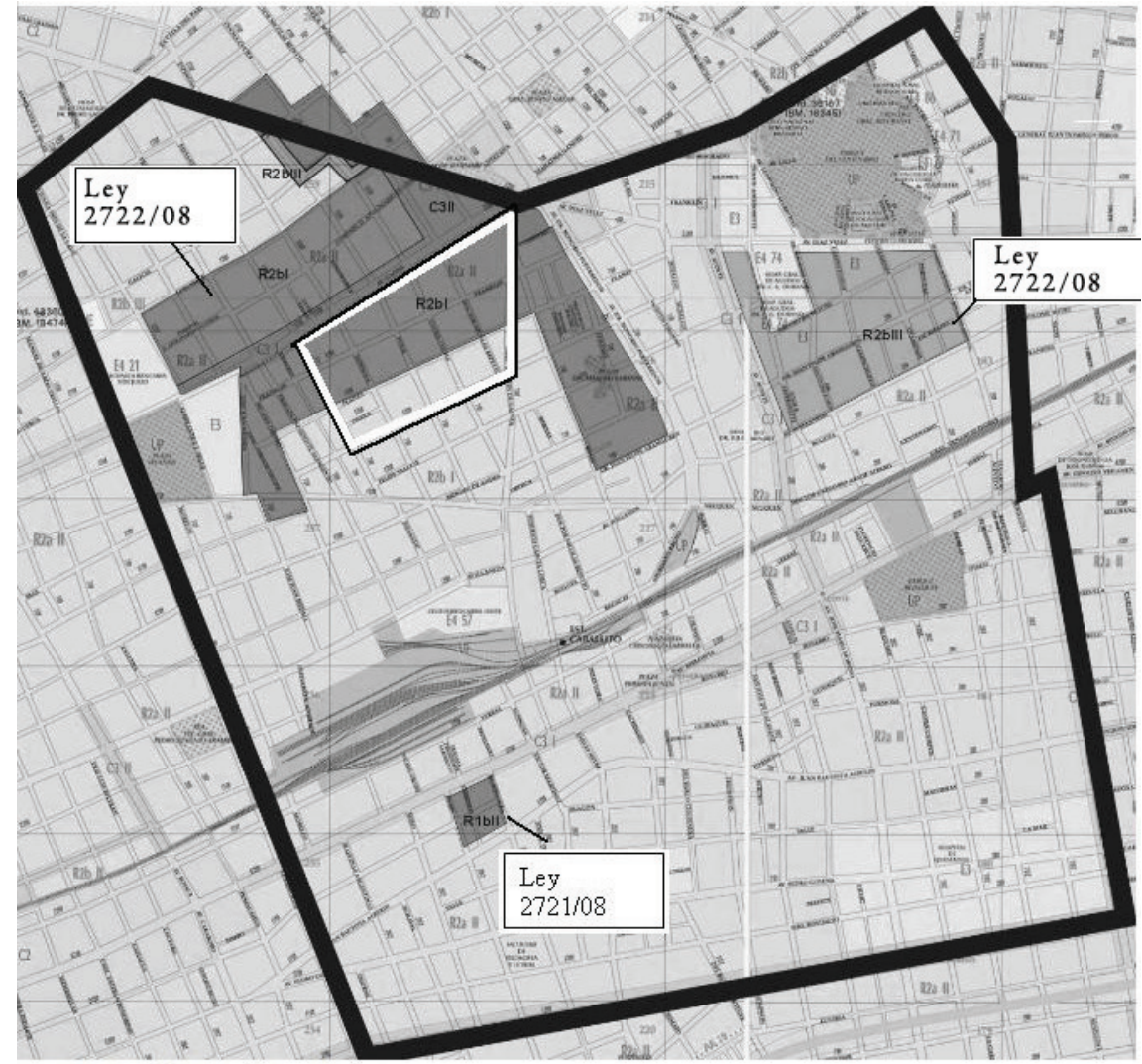

\section{Referencias}

Manzanas rezonificadas por dos leyes de la legislatura

Manzanas alcanzadas por el fallo de la Jueza Petrella

Límite del barrio de Caballito

FUENTE ELABORACIÓN PROPIA.

24 Nos referimos al fallo dictado por el juez de Primera Instancia, en lo Contencioso, Administrativo y Tributario $\mathrm{N}^{\circ} 8$, Osvaldo Otheguy, el día 26 de diciembre de 2007; y el fallo dictado por la jueza de Primera Instancia en lo Contencioso, Administrativo y Tributario $\mathrm{N}^{\circ} 1$, Helena Liberatori, el 21 de diciembre del mismo año. Ambos hacen lugar al pedido de no innovar en dos manzanas del barrio y solicitan al Ejecutivo que no otorgue permisos de obra en esas manzanas. Las manzanas contempladas en los fallos están dentro de aquellas que fueron rezonificadas por la legislatura. 


\section{Conclusiones}

Por medio del análisis del conflicto suscitado por las transformaciones urbanas en un barrio de Buenos Aires, hemos tratado de mostrar las ventajas que, sobre la sociología de los movimientos sociales, tiene una sociología del conflicto que trata de identificar su productividad social. Para ello se analizó dicha productividad en tres ámbitos analíticamente distintos, pero íntimamente relacionados entre sí: la territorialización, la irrupción en el espacio público y la actualización del derecho.

Sobre el primero de ellos, el conflicto produjo una revitalización del sentido de pertenencia de una población respecto de su espacio urbano. El intenso proceso de territorialización delimitó el barrio como zona que debía ser protegida, reactivó solidaridades sustentadas en la proximidad geográfica pero también social, y dejó sentadas las bases - bajo la forma de organizaciones, redes de vecinos que circulan información y un acervo de expertise- para otras controversias que se abrieron con posterioridad y que aún hoy están vigentes. ${ }^{25}$

La productividad del conflicto en el espacio público también se hizo evidente más allá del mero hecho de su difusión por los medios de comunicación, que sin duda desempeñaron un papel fundamental. El conflicto hizo visibles los costos sociales de un tipo de proyecto urbano que originalmente había sido visto como una actividad económica ejemplar en tiempos de recuperación económica. En el espacio público de la Ciudad de Buenos Aires, la pérdida de "calidad de vida" se impuso como un costo que no debía ser aceptado y Caballito se tornó referente de una diversidad de organizaciones que comenzaron a surgir con posterioridad en otros barrios de la ciudad afectados por la construcción de nuevas edificaciones, como Villa del Parque, Villa Pueyrredón y Villa Urquiza. De este modo, los efectos de socialización y aprendizaje del conflicto también se produjeron en espacios distintos al de los actores directamente involucrados.

Asimismo, el análisis mostró la importancia de identificar los diferentes espacios públicos o arenas donde se procesan los conflictos y, en particular, el modo en que la lógica de dichos espacios lleva a una reconfiguración de los mismos. Desde las protestas públicas en las calles, el conflicto transitó por espacios de deliberación diferentes, que ponderaron más un argumento que otro, interpelaron a nuevos actores y rediseñaron la delimitación del territorio que era preciso proteger. Resultó evidente que el ingreso del conflicto al ámbito judicial fue un momento de inflexión, ya que en esa instancia se logró que una demanda de "protección de la calidad de vida" se tradujese en un derecho exigible mediante el "argumento ambiental", que invocó el derecho a un medioambiente sano.

Finalmente, es destacable la productividad del conflicto en el ámbito del derecho. No solo se logró una suspensión de algunos proyectos que estaban transformando el espacio barrial, por medio de la resolución de una jueza que cambió el rumbo y el sentido de la regulación urbana, esgrimiendo de manera expresa el dere-

25 Vinculadas al reclamo por la construcción del Parque del Bicentenario en terrenos públicos que eran de uso ferroviario, hoy en desuso, y donde se planea construir grandes desarrollos residenciales. 
cho a un medioambiente adecuado, sino que incluso el conflicto llegó a movilizar al Poder Legislativo, logrando modificar algunos puntos del CPU.

La experiencia de Caballito es importante cuando se contrasta con otras. A manera de ejemplo está la delegación ${ }^{26}$ Benito Juárez, ubicada en el área central de la Ciudad de México. El auge constructivo de los últimos años implicó la construcción de casi 31.000 viviendas nuevas entre 2000 y 2007 (un incremento de casi el 24\%) (Informe Comisión de Investigación, 2007). Aunque las condiciones que dieron lugar a ese auge no son las mismas ${ }^{27}$ que en el caso de Caballito, las consecuencias, al menos tal como son percibidas por los residentes, son muy parecidas y dieron lugar a movilizaciones que esgrimían reivindicaciones similares.

Los residentes de esta delegación realizaron diversas protestas y manifestaciones callejeras y movilizaron algunas instituciones gubernamentales para oponerse a la construcción de nuevas viviendas. Sorprende la similitud de percepciones en torno al modo en que esto afecta su vida cotidiana. En el caso mexicano también aparece la percepción de una "especulación salvaje" de los promotores inmobiliarios que "construyen sin freno" y "sin considerar el impacto en la infraestructura" (De Alba González, 2009, p. 50). La necesidad de ampliar las capacidades de las redes de servicios públicos para poder soportar una mayor demanda, el incumplimiento de las normas de edificación (ruidos, gases, polvo, taponamiento de desagües con cemento, trabajo en horario no permitido, etcétera) y la transgresión a los límites de altura y volumen en el caso de algunas construcciones, forman parte del repertorio de quejas y denuncias de los residentes de la delegación (Cfr. Informe Comisión de Investigación, 2007).

Para dar una idea del modo como se procesan tales reclamos en la capital mexicana, es importante hacer notar la existencia de la Procuraduría Ambiental y del Ordenamiento Territorial (PAOT), que es una especie de "ombudsman ambiental" y que fue creada en 2000. A pesar de no contar con atribuciones jurídicamente vinculantes, su capacidad para emitir recomendaciones la ha convertido en un referente importante en los conflictos territoriales de la Ciudad de México y su intervención ha sido crucial para la suspensión de algunos proyectos impugnados por organizaciones vecinales. La existencia de un malestar generalizado y la creciente movilización en torno a estos temas se han expresado en el número de denuncias que la ciudadanía ha presentado ante la PAOT. Mientras en los años 2002 y 2003 se presentaba un promedio de quinientas denuncias por año, para 2009 ese número se había casi triplicado para llegar a 1.471 (Informe Comisión de Investigación, 2007). Casi un tercio de esas denuncias se referían a cambios en el uso del suelo, lo que indica con claridad que las transformaciones urbanas producto del auge inmo-

26 La Ciudad de México tiene dieciséis “delegaciones”. Esta delegación tenía en el año 2000 una población de un poco más de 360.000 habitantes, en unas 115.000 viviendas.

27 La creciente edificación en la delegación Benito Juárez es parte de la política de redensificación de las delegaciones centrales del Distrito Federal, a partir del denominado "Bando 2", que promovió la construcción de nuevas viviendas en las colonias centrales, restringiendo el crecimiento de la mancha urbana. 
biliario habían suscitado una inconformidad social muy similar a la de Caballito en Buenos Aires.

Sin embargo, lejos de convertirse en procedimientos que condujesen a una resolución en la que el juzgador expresara claramente argumentos jurídicos y arribara a una decisión respecto de las construcciones en disputa, los conflictos en torno a las transformaciones urbanas en la capital mexicana fueron a dar directamente a la discusión parlamentaria. Debido a que las protestas vecinales no lograron movilizar al Poder Judicial, en febrero de 2007 el Poder Legislativo de la ciudad integró una "Comisión de Investigación para Valorar el Impacto del Otorgamiento de Licencias y Manifestaciones de Construcción que han afectado el desarrollo urbano en Benito Juárez", formada por siete diputados y dos diputadas. Esa comisión se creó con el propósito de "conocer el impacto que ocasiona el presuntamente desmedido otorgamiento de licencias de construcción" en dicha circunscripción, y se dedicó fundamentalmente a la organización de foros vecinales, así como a llamar a funcionarios del gobierno de la ciudad a "comparecer" para explicar la situación. A pesar de la severidad del informe final de dicha Comisión, que señalaba la existencia de numerosas violaciones y que incluso habla de una "ruptura del tejido social", sus trabajos no desembocaron en una modificación de la legislación y tampoco llegaron a tener una influencia sobre el otorgamiento de permisos en el área urbana en cuestión.

Puede decirse que si bien los conflictos por transformaciones urbanas en la Ciudad de México llegaron a tener una cierta resonancia en el espacio público y movilizaron al Poder Legislativo, las consecuencias en el terreno jurídico fueron prácticamente nulas. Aunque no podemos ofrecer aquí un análisis detallado de las condiciones jurídicas de los procesos urbanos en México, sí podemos señalar que en la legislación existen mecanismos que pueden ser utilizados para movilizar al Poder Judicial. ${ }^{28}$ Recurrimos al caso de Benito Juárez, en el que no se produjo una movilización del Poder Judicial, para hacer notar que, a pesar de tratarse de conflictos similares, la juridificación de los mismos puede ser muy distinta entre una ciudad latinoamericana y otra.

Lo interesante, desde un punto de vista sociológico, es que, pese al escepticismo de algunas corrientes contemporáneas de la sociología del derecho sobre la posibilidad de que las normas jurídicas tengan una función regulatoria sobre la vida social (particularmente la que se inspira en la teoría de los sistemas sociales), ${ }^{29}$ lo que resalta del caso de Caballito es la fuerza de la idea regulatoria del derecho. Más allá del modo en que, en la práctica, los procesos sean efectivamente regulados (o no) por los dispositivos jurídicos, lo cierto es que la acción del conjunto de los actores participantes en el conflicto estuvo organizada por esa expectativa. Todos los actores, independientemente de su posición, veían en el derecho una fuente de regulación

28 Nos referimos al art. 180 de la Ley General del Equilibrio Ecológico y la Protección al Ambiente, que abre la posibilidad de que los vecinos afectados por obras que contravienen la normativa vigente y afectan su calidad de vida puedan exigir la revocación de los permisos correspondientes.

29 Véase nota 2 supra. 
de los procesos urbanos. Mientras esa expectativa esté presente en la acción social, tendremos que seguir tomando en serio la función regulatoria del derecho.

Entre las muchas vertientes que quedan por explorar, una es el modo en que la juridificación del conflicto, más allá de sus efectos inmediatos, puede convertirse en un referente de la acción. Es parte de una investigación en curso la exploración sociológica de los efectos sociales de la judicialización (una modalidad de la juridificación) de los conflictos relacionados con el medio urbano en América Latina. En esa línea, se indaga en los tipos de controversias que los originan, el modo en que se traducen las expectativas sociales sobre el territorio al lenguaje y las condiciones específicas del campo judicial; y, sobre todo, en los efectos que tienen dichos conflictos en la producción del orden urbano. OEURE

\section{Referencias bibliográficas}

Azuela, A. (2006). Visionarios y pragmáticos. Aproximación sociológica al derecho ambiental. México: Fonatamara.

Azuela, A. \& Mussetta, P. (2009). Algo más que el ambiente. Conflictos sociales en tres áreas naturales protegidas de México. Revista de Ciencias Sociales, segunda época (Universidad Nacional de Quilmes), 1(16), 191-215. Disponible en http://bit.ly/Zr3ezj

Baer, L. (2008). La producción reciente del espacio residencial de la Ciudad de Buenos Aires. Un análisis desde la dinámica del mercado inmobiliario formal en los 2000. Ponencia presentada en el Seminario "Ciudad y Programas de Hábitat", 4 y 5 de diciembre de 2008. Universidad General Sarmiento, Los Polvorines, Buenos Aires.

Centro de Estudios para el Desarrollo Económico Metropolitano (Cedem). (2003). El mercado inmobiliario en la Ciudad de Buenos Aires. Buenos Aires: Centro de Estudios para el Desarrollo Económico Metropolitano (Cedem)/Gobierno de la Ciudad de Buenos Aires (GCBA).

Cefaï, D. (2001). Les cadres de l'action collective définitions et problèmes. En D. Cefaï \& D. Trom (Eds.), Les formes de l'action collective. Mobilisations dans des arènes publiques (pp. 51-97). París: Éditions de l'École des hautes études en sciences sociales (EHESS), Collection Raisons Pratiques.

Chateauraynau, F. (2008). Des disputes ordinaires à la violence politique. L'analyse des controverses et la sociologie des conflits. París: Groupe de Sociologie Pragmatique et réflexive, l'École des Hautes Études en Sciences Sociales. Versión 9 de noviembre de 2008, disponible en http:// bit.ly/16n10UO

Ciccolella, P. \& Mignaqui, I. (2008). Metrópolis latinoamericanas: fragilidad del Estado, proyecto hegemónico y demandas ciudadanas. Algunas reflexiones a partir del caso de Buenos Aires. Cuadernos del CENDES (Centro de Estudios del Desarrollo, Buenos Aires), 25(69), 47-68. Disponible en http://bit.ly/17na3Fz

Coser, L. (1961). Las funciones del conflicto social. México, D.F.: Fondo de Cultura Económica.

De Alba González, M. (2009). Representaciones y prácticas sociales en torno a políticas urbanas. La movilización NIMBY frente a la redensificación de las zonas centrales de la Ciudad de México. Cultura y Representaciones Sociales, 3(6). Disponible en www.culturayrs.org.mx/ 
revista/num6/Dealba.pdf

Della Porta, D. \& Diani, M. (1999). Social movements. An introduction. Oxford: Blackwell.

Di Paola, M. E. (2008). El impacto ambiental acumulado y las construcciones en la Ciudad de Buenos Aires. Buenos Aires: Fundación Ambiente y Recursos Naturales. Disponible en http://www. foroambiental.org.ar/IMG/article_PDF/article_551.pdf

Duarte, J. (2006). Elmercado de suelo en la Ciudad de Buenos Aires. Análisis crítico de su funcionamiento y su relación con la estructura urbana y las politicas públicas del Gobierno de la Ciudad. Tesis de Licenciatura en Urbanismo. Instituto del Conurbano, Universidad General Sarmiento.

Gorelik, A. (1998). La grilla y el parque. Espacio público y cultura urbana en Buenos Aires, 1887-1936. Bernal: Universidad Nacional de Quilmes.

Melé, P. (2003a). Introduction: conflits, territoires et action publique. En P. Melé, C. Larrue \& M. Rosemberg (Coords.), Conflits et territoires (pp. 13-32). Tours: Presses Universitaires François-Rabelais, Maison des sciences de l'homme.

Melé, P. (2003b). Conflits urbains pour la protection de la nature dans une métropole mexicaine. En P. Melé, C., Larrue \& M. Rosemberg (Coords.), Conflits et territoires (pp. 103-117). Tours: Presses Universitaires François-Rabelais, Maison des sciences de l'homme.

Merlinsky, G. (2009). Atravesando el rio: La construcción social y política de la cuestión ambiental en Argentina. Dos estudios de caso en torno al conflicto por las plantas de celulosa en el Río Uruguay y al conflicto por el saneamiento de la Cuenca Matanza-Riachuelo. Tesis doctoral inédita. Facultad de Ciencias Sociales, Universidad de Buenos Aires/Université Paris 8.

Mignaqui, I. (1998). Dinámica inmobiliaria y transformaciones metropolitanas. La producción del espacio residencial en la Región Metropolitana de Buenos Aires en los 90. En C. Gorenstein $\&$ R. Bustos Cara (Comps.), Ciudades y regiones frente al avance de la globalización (pp. 255-283). Bahía Blanca: Editorial de la Universidad Nacional del Sur.

Naishtat, F. (2005). Ética pública de la protesta colectiva. En F. Schuster, F. Naishtat, G. Nardacchione \& S. Pereyra (Comps.). Tomar la palabra. Estudios sobre protesta social y acción colectiva en la Argentina contemporánea (pp. 25-42). Buenos Aires: Prometeo.

Nardacchione, G. (2005). La paradoja de las protestas vecinales bajo el menemismo. ¿Cómo generalizar la protesta defendiendo lo propio? En F. Schuster, F. Naishtat, G. Nardacchione \& S. Pereyra (Comps.). Tomar la palabra. Estudios sobre protesta social y acción colectiva en la Argentina contemporánea (pp. 193-218). Buenos Aires: Prometeo.

Petrella, A. (2008). Confictos entre desarrollo inmobiliario y protección ambiental. Ponencia presentada en el Congreso Internacional de Derecho Ambiental: Ordenamiento ambiental del territorio de las ciudades. Buenos Aires, 5 y 6 de noviembre de 2008. Disponible en http://bit. ly/10xV0UH

Rottlethuner, H. (1989). A purified sociology of law: Niklas Luhmann on the autonomy of the legal system. Law \& Society Review, 23(5), 779-797. doi: 10.2307/3053763

Sabatini, F. (1997). Conflictos ambientales y desarrollo sustentable de las regiones urbanas. EURE, 22(68), 77- 91. Disponible en http://bit.ly/12d5gF3

Simmel, G. [1918] (1964). Conflict. Nueva York: The Free Press of Glencoe.

Svampa, M. (2002). Las dimensiones de las nuevas protestas sociales. El Rodaballo (Buenos Aires), 14 (Invierno), 1-16. Disponible en http://www.maristellasvampa.net/archivos/ensayo12.pdf Szanjberg, D. (2010). Torres amuralladas. Su protagonismo en la densificación residencial de Buenos 
Aires desde los años 90. Buenos Aires: Nobuko.

Szanjberg, D. \& Cordara, C. (2007, abril). Las políticas urbanas en su laberinto II. El Código de Planeamiento Urbano de Buenos Aires o la quimera de la Planificación: la densificación vertical de la Avenida Pedro Goyena, en Caballito y Flores. Revista digital Café de la Ciudades, 6(54). Disponible en http://www.cafedelasciudades.com.ar/politica_54.htm

Tella, G. (2005). Rupturas y continuidades en el sistema de centralidades de Buenos Aires. En M. Welch Guerra (Ed.), Buenos Aires a la deriva. Transformaciones urbanas recientes (pp. 29-73). Buenos Aires: Biblos.

Teubner, G. (1991). Regulatory Law: Chronicle of a death foretold. Social \& Legal Studies, 1(4), 451475. Disponible en http://www.jura.uni-frankfurt.de/43829585/Regulatory_Law.pdf

Visacovsky, S. (2009). Imágenes de la clase media en la prensa escrita argentina durante la llamada crisis del 2001-2002. En S. Visacovsky \& E. Garguin (Comps.), Moralidades, economías e identidades de clase media. Estudios históricos y etnográficos (pp. 247-278). Buenos Aires: Antropofagia.

Welch Guerra, M. \& Valentini, P. (2005). Torres-jardín en Buenos Aires. Proyecciones de una tipología habitacional. En M. Welch Guerra (Ed.), Buenos Aires a la deriva. Transformaciones urbanas recientes (pp. 74-95). Buenos Aires: Biblos.

Zald, M. (1999). Cultura, ideología y creación de marcos estratégicos. En D. McAdam, J. D. McCarthy \& M. N. Zald (Comps.), Movimientos sociales: perspectivas comparadas (pp. 369-388). Madrid: Istmo.

\section{Fuentes}

Anuario Estadístico 2008. Disponible en http://www.estadistica.buenosaires.gov.ar

Asamblea Legislativa del Distrito Federal (2007). Benito Juárez. Una historia de impunidad. Avances del informe de la Comisión de Investigación para valorar el impacto del Otorgamiento de Licencias y Manifestaciones de construcción que han afectado el Desarrollo en Benito Juárez. México: Asamblea Legislativa del Distrito Federal.

Censo de Población, Hogares y Viviendas 2001 y 2010. Argentina: Instituto Nacional de Estadística y Censos (INDEC)

Fallo dictado por la jueza de Primera Instancia, en lo Contencioso, Administrativo y Tributario $\mathrm{N}^{\circ} 12$, Alejandra Petrella, el día 6 de noviembre de 2006.

Fallo dictado por el juez de Primera Instancia, en lo Contencioso, Administrativo y Tributario $\mathrm{N}^{\circ} 8$, Osvaldo Otheguy, el día 26 de diciembre de 2007.

Fallo dictado por la jueza de Primera Instancia en lo Contencioso, Administrativo y Tributario $\mathrm{N}^{\circ} 1$, Helena Liberatori, el 21 de diciembre de 2007.

Reporte Inmobiliario. Relevamiento en Parque Centenario. Enero 2008. Disponible en http://www. reporteinmobiliario.com/nuke/cat29-relevamientos.html 